\title{
Construção do Sistema Brasileiro de Vigilância Sanitária: argumentos para debate
}

\author{
Construction of the Brazilian Sanitary Surveillance System: \\ arguments to debate
}

M arismary H orsth DeSeta ${ }^{1}$

Sulamis Dain ${ }^{2}$

\footnotetext{
${ }^{1}$ Departamento de Administração e

Planejamento em Saúde, Escola Nacional de Saúde Pública Sergio Arouca, Fundação O swaldo Cruz. Rua Leopoldo Bulhões 1.480 , sala 728

M anguinhos. 21041-210

Rio deJaneiro RJ. deseta@ensp.fiocruz.br

${ }^{2}$ Instituto de M edicina

Social, U niversidade do

Estado do Rio deJaneiro.
}

Abstract This paper analyzes the Brazilian Sanitary SurveillanceSystem as an arrangement aimed at regulating and reducing health risks associated with consumption of products, use of health services and the environment. Historical, political and tax aspects were considered and their development compared with the $\mathrm{N}$ ational $\mathrm{H}$ ealth Surveillance System, which has received strong international cooperation. The comparison was based on the trajectory of their national systems and related federal agencies, as well as on criteria adopted for decentralization. The central category of analysis is federative coordination and was based on the framework of federalism and intergovernmental relations. The institutional context of health and sanitary surveillance presents strong political competition, instability in the project and probable reduction of the ability of federal coordination after thePact for $\mathrm{H}$ ealth. The National Sanitary Surveillance System due to its nature of public good and high externality in its field of action requires federal coordination for increasing the regional and local cooperation, also because of the structural heterogeneity of Brazilian municipalities.

Key words Regulation, Sanitary surveillance, $\mathrm{H}$ ealth surveillance, Intergovernmental relations, Federative coordination, Federation
Resumo Este artigo analisa a construção do Sistema N acional de Vigilância Sanitária, um arranjo voltado à regulação e redução dos riscos sanitários decorrentes do consumo de produtos, da prestação de serviços de saúde e do ambiente no Brasil. Consideraram-se aspectos históricos, políticos, fiscais e a conjuntura atual para cotejar seu desenvolvimento com o do Sistema $\mathrm{N}$ acional deVigilância em Saúde, quetem recebido intensa cooperação internacional. 0 cotejamento se baseou na trajetória de seus sistemas nacionais e respectivos serviços federais, bem como nos crité rios para descentralização. A análise teve como categoria central a coordenação federativa e se baseou no referencial do federalismo e das relações intergovernamentais. 0 contexto institucional da saúde e da vigilância sanitária apresenta forte competição política, instabilidade no proje to e provável redução da capacidade de coordenação federativa após o Pacto pela Saúde. 0 Sistema Nacional de Vigilância Sanitária, em razão da sua natureza de bem público e da alta externalidade de seu campo de ação, requer coordenaç̧ão federativa para incremento da cooperação regional e local e também pela heterogeneidade estrutural dos municípios brasileiros.

Palavras-chave Regulação, Vigilância sanitária, Vigilância epidemiológica, Relações intergovernamentais, Coordenação federativa, Federação 
Introdução

A Constituição de 1988 manteve, para o Brasil, 0 regime federativo, alçou a munici palidade a ente federado e aprofundou o processo de partilha das receitas, consolidando sob dois aspectos número de atores no processo decisório da federação etransferências financeiras - uma das mais descentralizadas federações do mundo. E o número de atores aumentou ainda mais, na esteira da descentralização das receitas e de busca de maior poder político. Assim, de 1988 a 2000, por fragmentação, os municípios existentes geraram outros 1.385 a 1.438 novos, sendo 253 apenas no estado do Rio Grande do Sul1,2.

O número é importante porque se relaciona com os graus de necessidade de coordenação federativa e de dificuldade no exercício dessa coordenação. M as desafio tão grande ou ainda maior resulta da diversidade do arranjo federativo, exacerbada pela fragmentação municipal. Os mais de 5.460 municípios formam um conjunto heterogêneo em vários aspectos: porte populacional; capacidadefiscal - degerar receitas efinanciar os gastos com a provisão de serviços públicos; e capacidade administrativa - de prover serviçose bens públicos à sua população. Exemplos polares de disparidade de porte são Borá e São Paulo capital, o menor e o maior municípios brasileiros, ambos no estado de São Paulo - o primeiro com população de 837 habitantes, conforme estimativa para 2009.

Além de aprofundar a cooperação financeira entre os entes e dispor sobre as competências de cada um deles - com relevo para as esferas federal e municipal -, a Constituição instituiu direitos de cidadania, dentre os quais o direito à saúde. Este, a ser assegurado mediante um conjunto de políticas sociais e econômicas que visem à redução do risco de doença e outros agravos e ao acesso universal e igualitário às ações e servi ços para sua promoção, proteção e recuperação ${ }^{3}$.

Para o setor saúde, desenhou-seuma novainstitucionalidadecom competências comuns aos três entes e enumeraram-se oito competências do SistemaÚ nico deSaúde(SUS). Uma delas era explícita: executar as ações de vigilância sanitária e epide miológica, bem como as de saúde do trabalhador ${ }^{3}$.

A definição legal da vigilância sanitária (VS) formalizou uma vasta área de atuação na qual ela teria a responsabilidade de intervir sobre riscos e problemas sanitários que decorressem dos processos de produção e consumo de bens, da prestação de serviços de interesse da saúde, ou do ambiente ${ }^{4}$. Essa ampla definição, forjada no bojo das propostas reformistas da saúde, condiciona um arranjo institucional tido como diferente do de outros países. A VS da federação singular, por ter o município como ente federativo, apresentaria um modelo nacional peculiar.

Esse caráter peculiar pode ser gerado pela simultaneidadede: (1) abordagem integral, em todo o ciclo de vida, dos produtos cujo controle sanitário écompetência exclusiva setorial - exemplificando, os medicamentos: dos estudos que antecedem o registro ao acompanhamento dos eventosadversos pós-utilização; (2) compartilhamento do controle sanitário com setores externos ao setor saúde, no caso dos alimentos, com a Agricultura; (3) extensa área de atuação: medicamentos; alimentos; serviços de saúdee outros nos quais a saúde tem interesse; tecnologias, procedimentos e ambientes. A extensa área de atuação per se concorre para essa estruturação peculiar.

Nos demais países, por meio de uma agência ou da administração direta setorial, o controle sanitário se dá desmembrado em: al imentos e medicamentos; medicamentosealimentosisoladamente, com o traço comum denão incorporar à vigilância o controlesanitário dos serviços de saúde. Nem só de diferenças se alimenta essa peculiaridade. Há também semelhanças: aqui, tal como nos Estados Unidos, a regulação dealimentose de medicamentos se organizou num lugar institucional separado da vigilância epidemiológica (VE).

Um aspecto central para esteartigo equecontribui para esse caráter peculiar é que desde 1999 seinstituiu o Sistema Nacional de Vigilância Sanitária (SNVS) com a participação, ainda que desigual, de três entes federados - e numa construção desigualmente negociada, mas tão cooperativa e conflitante como a construção federativa do SUS. Essa construção inconclusa é examinada neste artigo a fim de se incentivar o debate. O ptou-se por cotejar o SN VS vis-à-vis ao Sistema Nacional de Vigilância em Saúde, no seu componente de VE, a partir de três pressupostos: as estratégias, diversas, tiveram graus diferentes de sucesso, ese pode aprender com essas diferenças; a natureza da VSé especial, no campo da saúde, pelo caráter de Estado de muitas de suas ações; pelo desequilíbrio estrutural - grau de desigual dade entre entes federados e regiões quanto à disponibilidade de bens e infraestrutura e capacidade de gerar riqueza e bem-estar para suas populações - que marca a federação brasileira. E essa desigualdade precisa ser levada em conta, para ser reduzida.

$O$ contraponto entre o Sistema Nacional de Vigilância em Saúde e o SNVS, queabrigam práticas sanitárias diversas ${ }^{5}$, se justifica, visto que 
ambos: (1) integram o campo da proteção e pre venção; (2) aprofundam o processo de descentralização quando se iniciam os repasses financeiros específicos, de forma regular e automática, para as instâncias subnacionais; (3) explicitam a necessidade de se organizarem no plano nacional com um modelo sistêmico.

O cotejamento se baseou na trajetória de desenvolvimento dos sistemas nacionais das vigilâncias e dos serviços federais correspondentes e nos critérios para descentralização. A compreensão do desenvolvimento do SNVS vis-à-vis ao Sistema Nacional deV igilância em Saúde éainda mais necessária no momento atual.

Em primeiro lugar, éimportante frisar que há uma disputa de projetos, de poder institucional, de financiamento dos serviços das esferas subnacionais edas pesquisas e cooperaçõestécnicas, em torno do que se tem denominado como as "vigilâncias do campo da saúde" 5 - vigilância sanitária, epidemiológica, ambiental em saúdeevigilância em saúde do trabalhador - e seus modelos mais integrais e/ou unificados, ou mais articulados.

Essa disputa era esperada, na medida da re valorização das vigilâncias na esfera federal. Basta examinar a ascensão do serviço federal de VE na estrutura do ministério, ou a constituição da Agência N acional de Vigilância Sanitária (Anvisa), com certo grau de autonomia e independênciafinanceira.

A análise dessa disputa escapa aos objetivos deste artigo, mas não se pode omiti-la, visto que é em meio a ela que se tem a emissão da Portaria no 3.252, de 22 de dezembro de2009. Esta definiu vigilância em saúde como a reunião das diversas vigilâncias, mas referendou o SNVS ${ }^{6}$ e transformou o Sistema N acional deVigilância Epidemiológica (SNVE), previsto também em lei nacional ${ }^{7}$, em um dos subsistemas do Sistema N acional de Vigilância em Saúde ${ }^{8}$. Para evitar maiores enganos, a expressão Sistema Nacional de Vigilância em Saúde não receberá tratamento por meio de sigla neste artigo.

Em segundo lugar, o Pacto alterou as diretrizes para a organização e o financiamento da saúde e, obviamente, repercutiu nas vigilâncias do campo. Destacam-se a constituição do bloco de financiamento Vigilância em Saúde, com a agregação dos recursos destinados a cada uma das vigilâncias; e a mudança nos critérios de descentralização. Em consequência, esperam-se modificações institucionais nos serviços de vigilância das esferas subnacionais. Se essas esferas acompanham o formato federal para maior facilidade no recebimento de auxílio técnico e verbas fede- rais ${ }^{9}$, que dirá quando a mudança ocorre em um mecanismo de coordenação federativa, como as transferências financeiras intergovernamentais?

O termo "VE" é muito empregado no texto para maior clareza. De uso corrente no sistema de saúde brasileiro, ele tem um significado mais compartilhado nos seus diversos âmbitos - gestão, serviçose academia - eo conteúdo das ações mais bem definido em cada esfera de governo. 0 termo "vigilância em saúde" será empregado no seguinte sentido: vigilância em saúde pública é o nome proposto para a vigilância epidemiológica no final dos anos 198010; ou para referir-se ao sistema recentementeinstituído, que abriga também a vigilância ambiental em saúde e, desde 2007, a vigilância em saúde do trabalhador ${ }^{8}$.

0 texto está organizado em tópicos, na busca de maior compreensão. São eles: alguns constrangimentos na construção sistêmica da VS; contraponto com o sistema nacional de vigilância em saúde; e as considerações finais.

\section{Alguns constrangimentos na construção sistêmica da vigilância sanitária (VS)}

A VS éum bem público, como caracterizado pelas ciências econômicas ${ }^{5,11,12}$, visto que preenche os requisitos de indivisibilidade e de não rivalidade no consumo, que caracterizam esse tipo de bem. É também ação de Estado para intervir reduzindo riscos à saúde e buscando controlar a alta externalidade potencialmente negativa contida no seu campo de ação.

Sua capacidade de intervenção é assegurada mediante o poder de polícia administrativa no campo da saúde, sua face mais visível para a sociedade equea legitima socialmente. Seus modos de atuação compreendem atividades autorizativas (registro de produtos, licenciamento de estabelecimentos, autorização de funcionamento), normativas, de educação em saúde e de comunicação com a sociedade. As atividades normativas e autorizativas Ihe conferem caráter regulatório, de regulação no campo da saúde, com forte repercussão econômica ${ }^{13}$.

Anterior ao SUS, ela teve reconhecido seu potencial para qualificação do sistema de saúde por um segmento dos reformistas ${ }^{14}$ e integrou a agenda inconclusa da 8a Conferência Nacional de Saúde. Contudo, não integrou a pauta mais geral do SU S de negociação e descentralização ${ }^{15}$, iniciada pela rede de prestação de cuidados.

No SUS, de construção reconhecidamentefederativa, a VS precisa se organizar como um sis- 
tema nacional que atue colaborativamente para dar conta de sua missão. E esse sistema começa a se estruturar quando, além dos repasses financeiros automáticos e regulares específicos, se cria a Anvisa, a quem cabe a coordenação nacional do SNVS, no final dos anos 1990. N essa construção enfrentam-se desafios próprios da sua natureza e da necessidade que tem de, integrando o campo da saúde, intervir sobre tecnologias e atividades econômicas que repercutem nesse campo.

Uma parte dos desafios se deve aos altos requerimentos - técnicos, funcionais e políticos para muitas de suas ações. Estas abrangem, por exemplo, as de cunho fiscal, normativo e de comunicação - comunicação técnica de riscos para o SNVS e com a sociedade - na vasta área de atuação, concorrendo para um componente técnico diversificado e complexo.

Entre os requerimentos de ordem funcional e política, há a necessidade de várias ações serem executadas por agentes públicos - profissionais concursados ou comissionados - relativamente protegidosem razão do nível potencial menteal to de conflitos de interesse ${ }^{12}$. Esses altos requerimentos são difíceis de serem alcançados por todos os entes da federação desigual, pelo menos a médio prazo.

Além disso, no longo processo de desenvolvimento da VS, predominaram certa concentração do processo decisório na esfera federal euma quase total ausência das outras esferas de governo, inclusive no seu financiamento. Quase total pois há gastos realizados nas esferas subnacionais com a folha de pagamento do pessoal da vigilância - geralmente escasso e mal remunerado - eda estrutura- quase sempre precária, posta à sua disposição para trabalhar. Isso é gasto na função Saúde, mas é gasto na subfunção Vigilância Sanitária?

Afora os desafios próprios, há constrangimentos para a construção do SNVS situados na estrutura da federação e das relações intergovernamentais. A multiplicidade de entes federados, sua heterogeneidade estrutural e a histórica fragilidade da instância estadual - como exemplo, seu papel residual em todas as constituições republicanas, à exceção de suas competências tributárias ${ }^{13}$ - acarretam dificuldades na coordenação federativa para alcançar a cooperação. Esta seria ainda mais necessária para corrigir o desequilíbrio estrutural dos entes federados, que se relaciona com suas capacidades desiguais.

As relações intergovernamentais no campo da saúde são das mais cooperativas da federação, o que não significa inexistência de confli- tos ${ }^{16}$, e se caracteriza pela busca da solução conjunta de problemas - e as instâncias de negociação funcionam com regularidade. A cooperação, portanto, ultrapassa a cooperação financeira.

$\mathrm{Na} V \mathrm{~S}$, essa cooperação tripartite é recente. A penas em 2004 os municípios se incorporaram à negociação da descentralização da VS, pois ela priorizou a esfera estadual, diferentementedo que aconteceu na descentralização das ações de cuidado à saúde das pessoas. E essa incorporação se deu numa conjuntura de questionamento e mudança nos mecanismos de coordenação federativa - normas e transferências financeiras específicas - que viabilizavam o tipo de cooperação então vigente, num processo que culminou no Pacto.

Sobre a diversidade municipal, São Paulo e Borá... E a heterogeneidade estrutural dos serviços de VS? Serviços porque muitos são setores que desempenham uma função, e são poucos os que correspondem a organizações, com missão, objetivos e metas delineados, e algum grau de liberdade para realizar seu trabalho.

$\mathrm{Na}$ esfera federal, uma agência com crescente capacidadeadministrativa e condições institucionais invejáveis: mandato e estabilidade de dirigentes, capacidade de formação de receitas próprias, quadro de pessoal concursado e carreira diferenciada. N os estados, há diversidade nas atividades executadas e na estrutura, e elas geram distintas capacidades, competências e responsabilidades. Todavia, dois traços comuns: fragilidade, decorrente do papel residual dessa esfera na divisão das competências dos entes federativos; $\mathrm{e}$ dificuldade, embora com gradações, para exercer a coordenação federativa no seu âmbito.

Nos municípios, há também predominância dos de pequeno porte populacional - cerca de $25 \%$ deles têm até 5.000 habitantes, e quase $90 \%$ até 50.000 habitantes, segundo as estimativas populacionais do Instituto Brasileiro de Geografia e Estatística (IBGE). Os pequenos municípios costumam apresentar dificuldades na gestão e provisão de bens públicos a seus munícipes, e muitos somente criaram Secretarias e Conselhos de Saúde a partir da N orma O peracional Básica (NOB) n 96. Quais as consequências disso para a construção do SNVS? Pelo menos uma parece ser a não realização de ações típicas de VS por parte da maioria dos municípios, ou sua realização em caráter precário.

A descentralização na saúde éa expressão setorial de um movimento muito maior, e valores positivos foram e ainda são realçados na sua defesa. A descentralização como municipalização 
propiciou a expansão da rede de serviços deatenção à saúde das pessoas, mas recebeu numerosas críticas, que abrangem da qualificação do processo aos efeitos da descentralização: caráter tutelado da descentralização; descentralização incompleta; municipalização autárquica; atomização da rede de serviços; ineficiências e perdas de economia de escala; pulverização dos recursos ou sua insuficiência ${ }^{17-23}$.

Sobre essa descentral ização, predomina o reconhecimento demuitos avanços, a despeito dos problemas, mas o que se vem interrogando ésea descentralização da VS, por sua natureza e trabalho a realizar, pode seguir um caminho diferente do trilhado pelas ações de cuidado.

Tem-seaventado um pacto que leve em conta as características estruturais e funcionais dos entes e valorize a necessidade de ação ágil, coordenada e abrangenteterritorialmente, que caracteriza a vigilância sanitária ${ }^{5,12}$. Tanto para esse tipo de ação como para aumentar a cooperação, a coordenação pela esfera estadual é imprescindível, inclusive para a regional ização. Tal esfera também deve assegurar a execução de ações de controle sanitário que os municípios não tenham condição - técnica, organizacional ou política de fazer, em dado momento. Com isso aumentaria a cooperação entre o estado e os municípios, para ben efício da população, visto que, em várias regiões, a execução das ações anteriormente sob a responsabilidade dos estados tem-se reduzido assustadoramente, sem que os municípios as tenham assumido, e isso pode ter repercussões danosas.

Esse pacto específico, no conflituoso momento atual, parece distante de ser alcançado. $M$ as se considera ainda válida a afirmação segundo a qual as características e os atributos dos entes federados devem ser levados em conta no processo de descentralização de qualquer política, ainda mais de uma com as características da VS.

Outro grupo de constrangimentos abrange questões relacionadas à VS e sua descentralização, com destaque para a instabilidade da matriz deseu projeto. Com o Pacto pela Vida, acrescentaram-se alguns constrangimentos aos preexistentes. E os de agora parecem decorrer da competição de projetos para a área e da aparente re dução da coordenação federativa na construção do SNVS. Esse grupo de constrangimentos espera-se que aflore no cotejamento com o Sistema Nacional de Vigilância em Saúde.
O contraponto com o Sistema Nacional de Vigilância em Saúde

O Sistema Nacional deVigilância Epidemiológica (SNVE) se instituiu mediante uma lei nacional, em 1975, dez anos após a constituição da Unidade de Vigilância Epidemiológica na Organização Mundial da Saúde (OMS).

O Sistema Nacional de Vigilância em Saúde, que ele atualmente integra, tendo se transformado em um dos seus subsistemas, écomposto também pelo Subsistema $\mathrm{N}$ acional de Vigilância em Saúde Ambiental; pelo Sistema Nacional de Laboratórios de Saúde Pública e sistemas de informação, nos aspectos pertinentes à epidemiológica e ambiental; por programas de prevenção e controle de doenças; e pelas políticas nacionais deSaúde do Trabalhador e de Promoção da Saú$\mathrm{de}^{8}$. É coordenado nacionalmente pela Secretaria $N$ acional de Vigilância em Saúde do Ministério da Saúde (SVS/MS).

Reconhecendo a relevância dos demais subsistemas, a ênfase será colocada no SNVE, por ele representar a base para a construção do Sistema Nacional de Vigilância em Saúdee, também, pelos limites deste texto.

Trajetória de desenvolvimento dos sistemas nacionais das vigilâncias e fortal ecimento dos serviços federais correspondentes

O SNVE e o fortalecimento

do serviço federal correspondente

A Campanha de Erradicação da Varíola (CEV), que perdurou de 1966 a 1973, é considerada fundamental no desenvolvimento da VE no Brasil ${ }^{24-26}$. Ela pode ser considerada uma política prévia na construção do SNVE, visto que com ela se estruturou o componente estadual, por meio da instalação de Unidades de Vigilância Epidemiológica(UVE). Estasse organizaram com a cooperação técnica efinanceira federal27, mediantetransferências negociadas e com cofinanciamento pelos estados.

Na década de 1970, interferiram positivamente na qualidade das informações para a VE a implantação do formulário padronizado de declaração de óbito e o desenvolvimento, a partir de 1976, do Sistema N acional de Informações de M ortalidade ${ }^{28}$.

A 5ạ Conferência Nacional deSaúde, em 1975, seguida da regulamentação do SN VE mediante decreto, em 197629, foi desuma importância. N ela se discutiu um modelo básico a ser adaptado nos estados $^{27}$, e em sintonia com a formação federa- 
tiva da época, o sistema continha uma divisão do trabalho entre as esferas federal e estadual ${ }^{29}$.

A forte coordenação vertical do sistema pela esfera federal era assegurada por mecanismos de alinhamento dos governos locais durante o regime militar ${ }^{30}$, e se expressava no poder normativo e na supervisão da execução das ações ${ }^{29}$.

A formação de recursos humanos para 0 SNVE, esforço de várias décadas, tem dois momentos, após a CEV: num primeiro momento, um programa nacional de capacitação em VE, em 1983, que formou 3.000 profissionais para os estados $^{31}$. Destaque deve ser dado à parceria entre - Centro Nacional deEpidemiologia (Cenepi) ea Comissão de Epidemiologia da Associação Brasileira de Pós-Graduação em Saúde Coletiva (A brasco), criada em 1984. N essa parceria se formularam três planos de desenvolvimento da epidemiologia, ampliação da oferta de cursos de especialização e aumento da produção científica, e fortalecimento dos programas de pós-graduação stricto sensu ${ }^{32}$. E num segundo momento, após a criação do Cenepi, houve a elaboração de um leque de propostas de formação, de duração etitulação diversas. Para ofertá-los, montou-se uma rede de instituições formadoras, em 2004.

Quando se iniciaram os repasses financeiros regulares, a esfera estadual estava bastante estruturada. 0 Teto Financeiro de Epidemiologia e Controle de Doenças (TFECD) - depois denominado Teto Financeiro da Vigilância em Saúde (TFVS) - deu concretude às transferências automáticas para as esferas subnacionais, e a construção do sistema foi reforçada com a captação de recursos no Banco Mundial para os Projetos VigiSUSI ell.

Sucessivas normas promoveram a descentralização financeira e induziram iniciativas nas esferas subnacionais de governo; boa parte delas continua a receber incentivos após o Pacto.

Com a criação do Centro Nacional de Epidemiologia na Fundação N acional de Saúde (Funasa), em 1990, e sua transformação, em 2003, em Secretaria de Vigilância em Saúde (SVS/M S), há uma trajetória ascendentena hierarquia institucional - com apenas uma inflexão, a rejeição do projeto do Executivo federal de criação de uma Agência Federal de Prevenção e Controle de Doenças (Apec). N essa ascensão ocorreram a ampliação de áreas de atuação e a permanência do dirigente do serviço federal, Jarbas Barbosa Silva Júnior, configurando-se uma continuidade administrativa.

Buscava-se construir um modelo de práticas centrado na análise intensiva de informações e na montagem, em base nacional, de uma rede bastanteinternacionalizada - a RedeCIEVS, para o que se fazia necessário padronizar um conjunto de habilidades. $\mathrm{Na}$ adoção desse modelo difundido na articulação entre a OM S e o Center for Diseases Control and Prevention (CDC), com financiamento do Banco Mundial para os projetos VigiSUS I e II, expandiram-se propostas de formação, com destaque para o EPISUS, programa de formação de epidemiologistas de campo realizado com a participação do CDC.

$\mathrm{NaSV}$ S/M S, em 2007, incorporou-se a Saúde do Trabalhador ${ }^{33}$, que andara subsumida na estrutura do ministério. M as antes essa secretaria estendera sua esfera de influência para a VS, dentre outros fatores, mediante a incorporação de algumas ações básicas de VS na Programação Pactuada e Integrada da Vigilância em Saúde (PPI/VS) ${ }^{34}$ e da competência que Ihe foi atribuída para formular a política de VS, bem como regular e acompanhar seu contrato de gestão com o ministério.

A Portaria $n$ 0 3.252/2009 lista a vigilância sanitária entre as ações de promoção da saúde da população, vi gilância, proteção, prevenção e controle das doenças e agravos à saúde ${ }^{8}$, mas reconhece para ela um sistema nacional distinto. Enquanto isso, encontra-seem elaboração o VigiSUSIII, no qual seabre a possibilidade de criação deuma nova secretaria no M inistério da Saúde para suceder a Funasa.

O SNVS e o fortalecimento

do serviço federal correspondente

A 6a Conferência Nacional deSaúde, em 1976, não discutira a montagem de seu sistema, mas sim a nova legislação sanitária, que era necessário implementar. No mesmo ano, criou-se a Secretaria Nacional de Vigilância Sanitária, no M inistério da Saúde. Embora leis nacionais dos anos 1970 fizessem referência a atribuições dos serviços de VS das esferas subnacionais, foi em meados dos anos 1980 que se explicitou a necessidade de descentralização e maior articulação entre os serviços, na I Conferência Nacional de Saúde do Consumidor, em 1986.

Com a Portaria no 1.565/1994, sem êxito, tentou-seinstituir o SNVS com baseem um modelo que buscava uma ação mais integrada das vigilâncias sanitária, epidemiológica e em Saúde do Trabalhador, além de promover a articulação com o conjunto das ações assistenciais e com outros setores ${ }^{12}$.

O SNVS se instituiu após a implementação da N OB n 01/96 ea criação da Anvisa, o quenão significa a inexistência anterior de ações coope- 
rativas entre as esferas de governo em questões específicas. Em meio a uma crisequeincluía fraudeefal sificação de medicamentos e sem o prestimoso apoio da comunidade sanitária internacional; com a comunidade da saúde coletiva dividida - para não dizer, refratária; com o projeto VigiSUS em avançada negociação e em meio à Reforma do Estado empreendida no governo Fernando $\mathrm{H}$ enrique, por medida provisória transformada na Lei no 9.782/996, definiu-se a conformação do SNVS e atribuiu-se à Anvisa a responsabilidade de coordená-lo.

Ao instituir a Anvisa eseu modelo de gestão, colocou-se um fim na rotatividade dos postos de direção do órgão federal ${ }^{35}$ e se dispôs sobre a arrecadação das taxas de fiscalização, que tiveram seu escopo e valores majorados, aumentando a capacidade financeira da Anvisa.

A conjuntura em queseinstituíram a Agência e o SNVS diferiu muito daquela em que foram lançadas as bases estaduais do SNVE, na década de1970. Além do regime democrático da proliferação de entes - o município já era um ente federado -, as instâncias de pactuação estavam razoavelmenteestruturadas e experimentadas no processo de negociação federativa. A Anvisa elegeu como interlocutor privilegiado na discussão sobre a descentralização a esfera estadual, representada pela Câmara Técnica do Conselho Nacional deSecretários de Saúde(Conass) . A coordenação federativa que se exerceu junto aos estados foi mais efetiva do que a exercida junto aos municípios pelo que se expõe: os estados assinavam um instrumento, o Termo deAjustes e M etas (TAM), estabeleciam metas - incluindo, além das metas de inspeção, a formação de pessoal e as organizativas - e recebiam seus repasses. Com isso, os serviços de vigilância da esfera estadual iniciaram sua estruturação. Os municípios recebiam um valor per capita unificado nacionalmente. Embora se adotasse a classificação das ações de vigilância segundo níveis de complexidade, a exemplo da área assistencial, não se vinculou a realização das ações assim classificadas à modalidade de gestão na qual o ente estava enquadrado ${ }^{15}$.

A indução federal resultou na estruturação e modernização dos serviços estaduais de VS e estes ficariam com a responsabilidade de promover a descentralização das ações de VS no âmbito de seu território. A avaliação, por parte da Anvisa, de que isso não ocorreu, junto com a existência de saldos financeiros dos recursos repassados aos estados, teria motivado, após 2003, a introdução da esfera municipal no processo de pactuação.
Constituiu-se o Comitê Consultivo de Vigilância Sanitária da Comissão Intergestores Tripartite (CIT), composto por diretores da Anvi$\mathrm{sa}$, representantes do Conselho $\mathrm{Nacional}$ de $\mathrm{Se}$ cretários Municipais de Saúde (Conasems) e do Conass. Discutiram-senovas diretrizes para descentralização e financiamento que, após a aprovação pela $\mathrm{CIT}$, transformaram-se na Portaria no 2.473/2003 36 , um novo direcionamento incorporando o município.

Com o Pacto, deslocaram-se as funções do Comitê para o Grupo Técnico de Vigilância em Saúde(GTVS), da CIT, em queaVSéminoritária - fato que contribuiu, ainda que não exclusivamente, para aumentar o grau dedificuldadeeenfraquecer a coordenação federativa exercida pela Anvisa. Provavelmente, fatores ainda não identificados, relacionados à própria agência, aos demais membros do SNVS e à sua condução do processo também contribuíram para 0 aumento das dificuldades. M as um fator pode ser aqui citado: a cooperação com instituições acadêmicas, de desenho mais restrito relativamenteà $V E$, não alcançou o estabelecimento de um programa nacional de formação, apesar das numerosas capacitações técnicas realizadas, de caráter pontual.

A SVS/M Stem como projeto político a construção do Sistema N acional deVigilância em Saúde, para o qual a VS, intencionalmente ou não, também passou a contribuir, na medida em que se integraram à PPI/VS al gumas ações que seriam de responsabilidade do serviço municipal de VS. E o conteúdo desse projeto também mudou, visto que a vigilância integra, mas às vezes não integra, o modelo de vigilância em saúdeem processo de implantação no Brasil. Essa labilidade depende da condução da gestão, ou é reflexo de uma concessão ao modelo da vigilância da saúde, não discutido neste artigo?

\section{Critérios para descentralização}

Para o SNVE, de 1998 até 2009 as responsabilidades das três esferas de governo e a forma de financiamento foram estabelecidas por meio de normas do ministério ${ }^{37-39}$. Para o SNVS também, mas as normas apresentavam mudanças substanciais quanto a atores e conteúdo. Para os municípios, iniciam-se os repasses federais automáticos específicos para a VS em 1998, e o valor per capita éunificado nacional mente, sem o compromisso da realização de ações. Para os estados, a partir de 2000 houve negociação de compromissos, consubstanciados no Termo de Ajustes e M etas (TAM). Assim, as transferências 
como mecanismos de coordenação funcionaram melhor para os estados.

Os critérios para descentralização, que foram diversos para as vigilâncias sanitária eepidemiológica, encontram-se sistematizados no Quadro 1.

A análise das diferenças entre as duas matrizes de descentralização evidencia forte coordenação federativa na construção do SN VE e maior estabilidade desse projeto. $E$ ainda, além do maior número de repasses praticados pela vigilância em saúde, valores mais altos para cada um deles, em relação aos da VS. Sobressaem aspectos que evidenciam um desenho técnico mais apurado e estável da descentralização da VE: estratificação dos estados, valores per capita distintos para cada estrato, o que potencial mente contribui para maior equidade.

A cooperação financeira entre os entes se re velou mais estável e abrangente, em razão do estabelecimento de contrapartidas, para a vigilância em saúde do que para a VS. N esta, predominam astransferências federais que, inclusive, sustentaram quase que exclusivamente a estruturação dosserviços estaduais. Ressal va seja feita para o fato de, no escopo deste trabalho, não se terem buscado evidências da cooperação financeira entre os estados e os municípios nelesituados, nem no sentido horizontal.

\section{Considerações finais}

Tal como sucedeu na VE, a estruturação do SNVS se iniciou pela esfera estadual. Todavia, a construção do SNVS, iniciada em contexto histórico e social diverso, requereu pactuação e incorporação das demandas estaduais e, posteriormente, também das municipais. Assim, enfrentou um processo mais lento e difícil do que sob um governo autoritário ${ }^{32}$, mas não se quer rapidez e facilidade a esse preço.

Além de um desenho mais elaborado para a descentralização, quelhepossibilitou fortecoordenação vertical, a VE contou com maior aporte financeiro, sem competição por recursos orçamentários exclusivos da esfera federal; e um projeto mais estável, com modificações aparentementeincrementais. 0 desenho do Piso Variável de Vigilância e Promoção da Saúde ${ }^{8}$ corrobora a permanência dessa forte coordenação pela esfera federal.

No caso do SNVS, as transferências como mecanismos de coordenação federativa funcionaram melhor para os estados. Seu projeto se caracterizou por instabilidade da matriz, de tal forma que pareceu ter sido um atéo final de 2003; outro, de 2004 a 2007; e outro ainda, no período inicial após o Pacto. A regra constitucional da competência do SUS para essa atividade não foi suficiente para pautar a VS na agenda decisória federativa. Outros mecanismos facilitadores como exemplos, um programa nacional de formação e um sistema de informação interligando todos os entes - não se instalaram.

Com este artigo, pretendeu-se lançar luz sobre alguns aspectos da construção federativa da VS e abrir o debate sobre o caráter conflituoso que permeia esse processo, o que tem sido tratado como um tabu erotulado como uma questão corporativa.

A construção de um sistema nacional tem historicidade ehá o peso da cooperação - técnica e financeira - de organismos multilaterais e internacionais. Cresce rapidamente um consenso sobre repercussões da globalização na saúde, incapacidade dos governos nacionais para melhorar a qualidade de vida e do ambiente, assegurar bem-estar e saúde de suas populações. E também sobre a necessidade de respostas rápidas às chamadas emergências em saúde pública. M esmo com base nacional, uma vigilância global... Vigilância global para fazer uma analogia com a saúde global, também veiculada por organismos multilaterais, a OM S à frente.

\section{Colaboradores}

M H DeSeta concebeu eredigiu a primeira versão do artigo; S Dain orientou a tese que embasou boa parte do artigo. Ambas participaram da revisão final.

\section{Agradecimentos}

A ElizabeteVianna Delamarque, Lenice Gnocchi da Costa Reise M ariane $M$ artins, pela leitura atenta e sugestões. 
Quadro 1. Diferenciais na descentralização das vigilâncias sanitária e epidemiológica, 1998-2009.

\begin{tabular}{|c|c|c|}
\hline Diferenciais & Vigilância Epidemiológica & Vigilância Sanitária \\
\hline $\begin{array}{l}\text { Participação das três } \\
\text { esferas no financiamento }\end{array}$ & Sim & Não \\
\hline $\begin{array}{l}\text { Certificação das } \\
\text { esferas subnacionais }\end{array}$ & Sim, até a Portaria n³.252/2009 & Não \\
\hline $\begin{array}{l}\text { Captação de } \\
\text { empréstimos externos }\end{array}$ & $\begin{array}{l}\text { Sim; VigiSUS I e II (Banco Mundial); } \\
\text { VigiSUS III (em negociação) }\end{array}$ & Não \\
\hline Recursos adicionais & PREVISTOS & NÃO PREVISTOS \\
\hline Estratificação estadual & $\begin{array}{l}\text { Sim; três estratos até 2003; } \\
\text { quatro estratos após } 2003\end{array}$ & Não; valor per capita único \\
\hline Contrapartida & $\begin{array}{l}20 \%, 30 \%, 40 \% \text { (conforme o estrato } \\
1,2,3 \text { ) até } 2003,20 \%, 30 \%, 35 \% \text { e } \\
40 \% \text { (conforme o estrato 1, } 2,3 \text { e } 4 \text { ) } \\
\text { após } 2004\end{array}$ & Não exigida, caráter formal \\
\hline $\begin{array}{l}\text { Composição dos tetos } \\
\text { financeiros e repasses }\end{array}$ & $\begin{array}{l}\text { Teto Financeiro de Epidemiologia e } \\
\text { Controle de Doenças (TFECD) } \\
\text { composto de três parcelas, que variam } \\
\text { conforme estrato: } \\
\text { (1) valor per capita/ano, R\$ } 4,08 \text { a } R \$ \\
\text { 1,80; ( } 2 \text { ) valor correspondente à área } \\
\text { do estado em } \mathrm{km}^{2} / \text { ano: de } \mathrm{R} \$ 3,00 \text { a } \\
\mathrm{R} \$ 1,20 ;(3) \text { incentivo à } \\
\text { descentralização - agregado ao teto } \\
\text { municipal, após certificação: per } \\
\text { capita igual para todos os estratos, no } \\
\text { valor de R\$ } 0,48 \text { por ano }\end{array}$ & $\begin{array}{l}\text { De } 1998 \text { a 2003: (a) Para os } \\
\text { municípios: valor per capita de R\$ } \\
\text { 0,25/ano (PBVS); (b) Para os estados: } \\
\text { soma de duas parcelas: (1) repartição } \\
\text { das Taxas de Fiscalização em } \\
\text { Vigilância Sanitária (TFVS); } \\
\text { (2) repasse para ações de média e alta } \\
\text { complexidades (M AC Visa): per } \\
\text { capita de R\$ 0,15/hab/ano }\end{array}$ \\
\hline $\begin{array}{l}\text { Incentivo à } \\
\text { descentralização }\end{array}$ & $\begin{array}{l}\text { Agregado ao teto municipal, } \\
\text { conforme disposto acima }\end{array}$ & $\begin{array}{l}\text { Subtraído do MAC Visa estadual; do } \\
\text { valor per capita de } \mathrm{R} \$ 0,15 / \text { hab/ano, } \\
\text { no mínimo } \mathrm{R} \$ 0,06 / \text { hab/ano para os } \\
\text { municípios }\end{array}$ \\
\hline $\begin{array}{l}\text { Mudanças } \\
\text { introduzidas: } \\
\text { repasses e critérios }\end{array}$ & $\begin{array}{l}\text { Sem outras modificações, exceto: } \\
\text { (1) Criação do quarto estrato estadual } \\
\left.\text { (Portaria } n^{\circ} 1.172 / 04\right) \text {, e as que } \\
\text { decorreram dessa criação; } \\
\text { (2) M ajoração dos valores per capita, } \\
\text { de } R \$ 4,08 \text { para } R \$ 4,80 \text { e de } R \$ 1,80 \\
\text { para } R \$ 1,84\end{array}$ & $\begin{array}{l}\text { Portaria no 2.473/2003 - para os } \\
\text { municípios que aderissem à } \\
\text { descentralização: (a) R\$ 0,10/hab/ano, } \\
\text { deduzido do teto estadual; (b) R\$ } \\
0,10 / h a b / a n o, \text { alocado pela Anvisa } \\
\text { Algumas ações da sanitária passaram a } \\
\text { integrar a PPI da vigilância em saúde } \\
\text { Portaria GM no 1.998/2007: } \\
\text { (a) Piso estruturante: R\$ 0,36/hab/ano } \\
\text { (só para municípios); (b) Piso } \\
\text { estratégico: valor per capita de } \\
\mathrm{R} \$ 0,21 \text { por habitante/ano (para entes } \\
\text { subnacionais que pactuassem) }\end{array}$ \\
\hline $\begin{array}{l}\text { Com a Portaria } \\
n^{\circ} 3.252 / 2009\end{array}$ & $\begin{array}{l}\text { I - Piso Fixo de Vigilância e } \\
\text { Promoção da Saúde: valor per capita, } \\
\text { segundo o estrato; II - Piso Variável de } \\
\text { Vigilância e Promoção da Saúde: } \\
\text { incentivos, conforme normatização } \\
\text { específica para Núcleos H ospitalares } \\
\text { de Epidemiologia; Sistema de } \\
\text { Verificação de Ó bito; Sistemas de } \\
\text { Registro de Câncer de Base } \\
\text { Populacional; ...; e outros que sejam } \\
\text { instituídos. }\end{array}$ & $\begin{array}{l}\text { I - Piso Fixo de Vigilância Sanitária - } \\
\text { PFVisa, composto pelo piso } \\
\text { estruturante e piso estratégico, } \\
\text { acrescido dos valores referentes ao } \\
\text { Finlacen-Visa; } \\
\text { II - Piso Variável de Vigilância } \\
\text { Sanitária: incentivos, conforme } \\
\text { normatização específica, para gestão } \\
\text { de pessoas, política de educação } \\
\text { permanente; e outros que sejam } \\
\text { instituídos. }\end{array}$ \\
\hline
\end{tabular}

Fonte: Elaboração própria, a partir de várias portarias listadas nas referências e disponíveis no Saúde Legis (http://portal2.saude.gov.br/saudelegis). 


\section{Referências}

1. Tomio FRL. A criação de municípios após a Constituição de 1988. Rev Bras Ci Soc 2002; 17(48):61-89.

2. Tomio FRL. Federalismo, municípios e decisões legislativas: a criação de municípios no Rio Grande do Sul. Rev Sociol Polit 2005; (24):123-148.

3. Brasil. Constituição da República Federativa do Brasil: texto constitucional promulgado em 5 de outubro de 1988, com as alterações adotadas pelas Emendas Constitucionais no $1 / 92$ a 26/2000 e pelas Emendas Constitucionais de Revisão no 1 a 6/94. Brasília: Senado Federal; 2000.

4. Lei $\mathrm{n}$ - 8.080, de 19 de setembro de 1990. Dispõe sobre as condições para a promoção, proteção e recuperação da saúde, a organização e o funcionamento dos serviços correspondentes e dá outras providências. Diário O ficial da União 1990; 19 set.

5. De Seta MH, Reis LGC. As vigilâncias do campo da saúde: aportes e implicações para a gestão de sistemas e de serviços de saúde. In: Oliveira RG, Grabois V, M endes Júnior WVO, organizadores. Qualificação de gestores do SUS. Rio de Janeiro: EAD/ Ensp; 2009. p. 201-347.

6. Lei $n=9.782$, de 26 de janeiro de 1999. Define 0 Sistema Nacional de Vigilância Sanitária e cria a Agência Nacional de Vigilância Sanitária, e dá outras providências. Diário Oficial da União 1999; 27 jan.

7. Lei ํㅡ 6.229, de 17 de julho de 1975. Dispõe sobre a organização do Sistema Nacional de Saúde. Diário O ficial da União 1975; 18 jul.

8. Portaria MS/GM $\mathrm{n} 03.252$, de 22 de dezembro de 2009. Aprova as diretrizes para execução e financiamento das ações de Vigilância em Saúde pela U nião, Estados, Distrito Federal e Municípios. Diário Oficial da União 2009; 23 dez.

9. Abrucio FL. Os barões da federação: os governadores e a redemocratização brasileira. São Paulo: Hucitec/ USP; 1998.

10. Waldman EA. Usos da vigilância e da monitorização em saúde pública. Inf Epidemiol SUS 1998; 7(3):7-26.

11. Medici A, Barros BW. Políticas de saúde e blocos econômicos. In: Biasoto Junior G, Silva PLB, Dain S. Regulação do setor saúde nas Américas: as relações entre o público e o privado numa abordagem sistêmica. Brasília: Organização Pan-Americana da Saúde; 2006. p. 71-106.

12. De Seta MH. A construção do Sistema Nacional de Vigilância Sanitária: uma análise das relações intergovernamentais na perspectiva do federalismo [tese]. Rio de Janeiro: Instituto de Medicina Social, Universidade do Estado do Rio de Janeiro; 2007.

13. O’D wyer G, Tavares M FL, De Seta M H. O desafio de operacionalizar as ações de vigilância sanitária no âmbito da promoção da saúde e no locus saúde da família. Interface 2007; 11(23):467-484.
14. Comissão Nacional da Reforma Sanitária (CNRS). Documentos [da] Comissão Nacional de Reforma Sanitária. Rio de Janeiro: Comissão Nacional da Reforma Sanitária; 1987. (Documentos, 3).

15. De Seta MH, Silva JAA. A gestão em vigilância sanitária. In: Conferência Nacional de Vigilância Sanitária, 1; 2001; Brasília. p. 71-83.

16. Abrucio FL, Costa VM F. Reforma do Estado e o contexto federativo brasileiro. São Paulo: Fundação Konrad Adenauer; 1999.

17. Vianna SM. A descentralização tutelada. Saúde Debate 1992; 35:35-38.

18. Carvalho G. A inconstitucional administração pósconstitucional do SUS através de normas operacionais. Cien Saude Colet 2001; 6(2):435-444.

19. Cordeiro H. Descentralização, universalidade e eqüidade nas reformas da saúde. Cien Saude Colet 2001; 6(2):319-328.

20. M isoczky MCA. A institucionalização do Sistema Ú nico de Saúde (SUS) sob a ótica das relações entre as esferas de governo da federação; 2001. [acessado 2007 dez 29]. Disponível em http://pdgsaude. ea.ufrgs.br/principal.htm

21. Marques RM, M endes A. A política de incentivos do Ministério da Saúde para a atenção básica: uma ameaça à autonomia dos gestores municipais e ao princípio da integralidade? Cad Saude Publica 2002; 18(Supl.):S163-S171.

22. M iranda AS. Análise estratégica dos arranjos decisórios na Comissão Intergestores Tripartite do Sistema Ú nico de Saúde [tese]. Salvador: Instituto de Saúde Coletiva, Universidade Federal da Bahia; 2003.

23. Pestana MVC, M endes EV. Pacto de gestão: da municipalização autárquica à regionalização cooperativa. Belo H orizonte: Secretaria de Estado de Saúde; 2004.

24. Silva Jr. JB. Epidemiologia em serviço: uma avaliação de desempenho do Sistema Nacional de Vigilância em Saúde [tese]. Campinas: Universidade Estadual de Campinas; 2004.

25. Waldman E, Freitas FRM . A vigilância epidemiológica e sua interface com as práticas da vigilância sanitária. In: Costa EA, editor. Vigilância sanitária: desvendando o enigma. Salvador: EdUFBA; 2008. p. 135-148.

26. Gazêta AAB, Carvalho DM, Tura LFR, Gaze R. A campanha de erradicação da varíola no Brasil e a instituição do sistema nacional de vigilância epidemiológica. Cad Saude Colet 2005; 13(2):323-338.

27. V Conferência Nacional de Saúde. Anais da V Conferência Nacional de Saúde. Brasília; 1975. [acessado 2006 set 20]. Disponível em: http://portal.saude. gov.br/portal/arquivos/pdf/5_CNS_anais.pdf

28. Waldman E, Silva LJ, Monteiro CA. Trajetória das doenças infecciosas: da eliminação da poliomielite à reintrodução da cólera. Informe Epidemiológico do SUS 1999; 8(3):5-47. 
29. Decreto $n-78.231$, de 12 de agosto de 1976. Regulamenta a Lei $n=6.259$, de 30 de outubro de 1975, que dispõe sobre a organização das ações de Vigilância Epidemiológica, e dá outras providências. Diário O ficial da União 1976; 13 ago.

30. Arretche MTS. Políticas sociais no Brasil: descentralização em um Estado federativo. Rev Bras Ci Soc 1999; 14(40):111-141.

31. Carvalho MS, Marzochi KBF. Avaliação da prática de vigilância epidemiológica nos serviços públicos de saúde no Brasil. Rev Saude Publica 1992; 26(2):3457.

32. Barata RCB. Formação em epidemiologia no Brasil. Rio de Janeiro; 2005. [acessado 2005 dez 7]. Disponível em: http://www.abrasco.org.br/grupos/ arquivos/20060718160633.pdf

33. Portaria MS/GM № 1.956, de 14 de agosto de 2007. Dispõe sobre a coordenação das ações relativas à saúde do trabalhador no âmbito do Ministério da Saúde. Diário Oficial da U nião 2007; 15 ago.

34. Instrução N ormativa SVS no 1 , de 8 de dezembro de 2003. Estabelece procedimentos para elaboração, implementação e acompanhamento da PPIVS. Diário Oficial da União 2003; 9 dez.

35. Souto AC. Saúde e política: a vigilância sanitária no Brasil 1976-1994. São Paulo: Sobravime; 2004.

36. Portaria M S/GM no 2.473, de 29 de dezembro de 2003. Estabelece as normas para a pactuação fixando as responsabilidades dos três entes federados na execução das ações de média e alta complexidade na área de vigilância sanitária. Diário Oficial da União 2004; 2 jan.

37. Portaria no 1.399/M S/GM, de 15 de dezembro de 1999. Regulamenta a NOB SUS $01 / 96$ no que se refere às competências dos entes federados, na área de epidemiologia e controle de doenças, define a sistemática de financiamento e dá outras providências. Diário Oficial da União 1999; 16 dez.

38. Portaria no 950, de 23 de dezembro de 1999. Define os valores anuais per capita e por quilômetro quadrado, destinados à composição do teto financeiro de epidemiologia e controle de doenças. Diário Oficial da União 1999; 24 dez.

39. Portaria MS/GM nํ 1.172, de 15 de junho de 2004. Regulamenta a NOB SUS 01/96 no que se refere às competências dos entes federados, na área de Vigilância em Saúde, define a sistemática de financiamento e dá outras providências. Diário Oficial da U nião 2004; 17 jun. 